\title{
Correction: A Prediction Rule to Stratify Mortality Risk of Patients with Pulmonary Tuberculosis
}

\author{
Helder Novais Bastos, Nuno S. Osório, António Gil Castro, Angélica Ramos, \\ Teresa Carvalho, Leonor Meira, David Araújo, Leonor Almeida, Rita Boaventura, \\ Patrícia Fragata, Catarina Chaves, Patrício Costa, Miguel Portela, Ivo Ferreira, Sara \\ Pinto Magalhães, Fernando Rodrigues, Rui Sarmento Castro, Raquel Duarte, João \\ Tiago Guimarães, Margarida Saraiva
}

The raw data underlying the results of this paper are missing from the list of Supporting Information. The authors have provided the data as Supporting Information file S1 Data. With this correction [1], all relevant data are now provided.

\section{Supporting information}

S1 Data. Supplementary dataset. This file includes supplementary data. (XLSX)

\section{Reference}

1. Bastos HN, Osório NS, Castro AG, Ramos A, Carvalho T, Meira L, et al. (2016) A Prediction Rule to Stratify Mortality Risk of Patients with Pulmonary Tuberculosis. PLoS ONE 11(9): e0162797. https:// doi.org/10.1371/journal.pone.0162797 PMID: 27636095

\section{G openaccess}

Citation: Bastos HN, Osório NS, Castro AG, Ramos A, Carvalho T, Meira L, et al. (2020) Correction: A Prediction Rule to Stratify Mortality Risk of Patients with Pulmonary Tuberculosis. PLoS ONE 15(11): e0242455. https://doi.org/10.1371/journal. pone. 0242455

Published: November 11, 2020

Copyright: @ 2020 Bastos et al. This is an open access article distributed under the terms of the Creative Commons Attribution License, which permits unrestricted use, distribution, and reproduction in any medium, provided the original author and source are credited. 